\title{
A survey of the initial referral of children to an ophthalmology department
}

\author{
Wang Yu-dong, J R Thompson, D B Goulstine, A R Rosenthal
}

\begin{abstract}
We report on a survey of the referral of 525 children making their first visit to an ophthalmology department. Information was gathered by interviewing the parents and reviewing the case notes. Parents and relatives initiated the referrals in 223 cases (42\%) and health visitors initiated a further 123 cases (23\%). General practitioners were rarely the first to notice a condition, though they played a major part in the subsequent referral process. Of 556 reasons for referral squint was the most important (319 cases, 57\%), followed by poor vision (106 cases, 19\%). There were 44 confirmed cases of amblyopia, of which 15(34\%) were not detected until the child was aged 5 years or over. The overall accuracy of referral was $66 \%$ (367 reasons for referral confirmed). In 109 cases (21\%) the child was found to be normal. Parents and relatives first noticed $54 \%$ of cases of confirmed squint but only $15 \%$ of the cases of poor vision. Health professionals, especially health visitors, were of great importance in first detecting poor vision.
\end{abstract}

Several studies have been conducted on the referral of adults to hospital eye services by general practitioners and ophthalmic opticians..$^{1-5}$ However, no studies of the referral of children to an ophthalmology department have been described previously.

The aim of this study was to investigate the process whereby children are referred to the outpatient clinics of an ophthalmology department. In particular we were concerned to evaluate the accuracy of the referral diagnoses and to assess the extent of unnecessary referrals.

\section{Material and methods}

Department of Ophthalmology, Clinical Sciences Building, Leicester Royal Infirmary, PO Box 65, Leicester LE2 7LX W Yu-dong

J R Thompson

D B Goulstine

A R Rosenthal

Correspondence to:

Dr John Thompson.

Accepted for publication

10 April 1990

Table 1 Number of referrals by age and sex

\begin{tabular}{|c|c|c|c|c|c|c|c|c|c|c|c|c|c|c|c|c|c|}
\hline \multirow[t]{2}{*}{ Sex } & \multicolumn{17}{|c|}{ Age (years) } \\
\hline & 0 & $l$ & 2 & 3 & 4 & 5 & 6 & 7 & 8 & 9 & 10 & 11 & 12 & 13 & 14 & 15 & 16 \\
\hline $\begin{array}{l}\text { Male } \\
\text { Female }\end{array}$ & $\begin{array}{l}66 \\
48\end{array}$ & $\begin{array}{l}37 \\
27\end{array}$ & $\begin{array}{l}22 \\
16\end{array}$ & $\begin{array}{l}55 \\
46\end{array}$ & $\begin{array}{l}16 \\
17\end{array}$ & $\begin{array}{l}24 \\
21\end{array}$ & $\begin{array}{l}13 \\
11\end{array}$ & $\begin{array}{l}18 \\
14\end{array}$ & $\begin{array}{l}10 \\
10\end{array}$ & $\begin{array}{l}6 \\
8\end{array}$ & $\begin{array}{l}1 \\
8\end{array}$ & $\begin{array}{l}8 \\
5\end{array}$ & $\begin{array}{l}2 \\
4\end{array}$ & $\begin{array}{l}5 \\
1\end{array}$ & $\begin{array}{l}0 \\
3\end{array}$ & $\begin{array}{l}1 \\
0\end{array}$ & 2 \\
\hline
\end{tabular}
first time referrals to the outpatient clinics of the eye department of the Royal Infirmary in Leicester, England, were monitored. The Department of Ophthalmology of Leicester Royal Infirmary is the only hospital eye department serving the National Health Service in Leicestershire. The hospital runs peripheral eye clinics in some of the towns in Leicestershire, and therefore the patients seen at the Royal Infirmary
Table 2 The ethnic origin of the children from Leicester City

\begin{tabular}{|c|c|c|}
\hline & Referral survey & Council survey \\
\hline & $\begin{array}{l}\text { Leicester City } \\
\text { Postcode } \\
\text { (n=395) }\end{array}$ & $\begin{array}{l}\text { Leicester City } \\
(n=67340)\end{array}$ \\
\hline $\begin{array}{l}\text { Caucasian } \\
\text { Asian } \\
\text { Others } \\
\text { Total }\end{array}$ & $\begin{array}{r}67 \% \\
30 \% \\
3 \% \\
100 \%\end{array}$ & $\begin{array}{r}\mathbf{6 6 \%} \\
30 \% \\
4 \% \\
100 \%\end{array}$ \\
\hline
\end{tabular}

were mostly from the City of Leicester and its surrounding suburbs. All children aged under 17 who were referred to the service were included in the survey. Those initially seen in the eye casualty department were not included.

For the purposes of this survey an initial visit was defined as the first visit to any ophthalmology department for the suspected condition, and the child's age was taken as at the date of referral.

Data were collected by a single ophthalmologist (WYD) by means of an interview with the parents and the careful reading of case notes and referral letters. Subsequently each child was followed up until a definitive diagnosis was made.

The data collected on each child were date of birth, sex, race, the date when the suspected defect was first noticed, the person who first noticed it, the dates of first contact with health agents prior to referral to the hospital, the date of referral to the hospital, reports of symptoms, reasons and purpose of referral, and the diagnoses and other results of the examination by the child's ophthalmologist or orthoptist.

The accuracy of referral was assessed by comparing the reasons for referral with the final diagnosis. The reasons for referral were considered accurate if the primary diagnosis suggested by the last contacted referring agent was confirmed by the ophthalmologist or orthoptist, or if the symptoms reported corresponded to the final diagnosis.

\section{Results}

During the four months of the survey 539

Table 3 The person who first noticed the suspected defect

\begin{tabular}{llc}
\hline & Number & Percentage \\
\hline Parents or relatives & 223 & 42 \\
HV & 123 & 23 \\
PMT & 59 & 11 \\
Child & 23 & 4 \\
School Nurse & 22 & 4 \\
CMO or SMO & 21 & 4 \\
Paediatric Services & 20 & 4 \\
GP & 15 & 3 \\
Others & 19 & 4 \\
Total & 525 & 100 \\
\hline
\end{tabular}
$\mathrm{HV}=$ health visitor. $\mathrm{PMT}=$ physiological measurement technician.
$\mathrm{CMO}=$ community medical officer. $\mathrm{SMO}=$ school medical officer. $\mathrm{CMO}=$ community medica
$\mathrm{GP}=$ general practitioner. 
Table 4 Reason for the referral

\begin{tabular}{lcc}
\hline & Number & Percentage \\
\hline Squint & 319 & 57 \\
Poor vision & 106 & 19 \\
Runny eyes & 23 & 4 \\
Lump on lid & 20 & 4 \\
Epicanthus & 10 & 2 \\
Family history & 8 & 1 \\
Other & 70 & 13 \\
Total & $556^{\star}$ & 100 \\
\hline
\end{tabular}

*In 31 cases two reasons were given.

children were referred to the hospital clinics, of these 14 were lost to follow-up and thus did not have a final diagnosis. The results below refer to the remaining 525 children

Table 1 shows the age and sex distribution of the referrals. The mean age at referral was $3 \cdot 7$ years, and $286(55 \%)$ of the cases were male. Males and females were similar in their age distribution. The most frequent attenders were in the groups aged under 1 year and aged 3 years, representing $28 \%$ and $19 \%$ of the total respectively. These peaks correspond to nine months and 3.5 years' screening. Nearly $70 \%$ of children were aged under 5 . Those aged 12-16 accounted for only $3 \%$.

The ethnic origins of the children with Leicester City Postcodes are shown in Table 2. A comparison can be made with the estimated breakdown of the population of children aged under 16 produced by the City Council in $1983 .{ }^{\circ}$ The percentages are very similar.

Table 3 shows the person who first noticed the suspected defect that led to the eventual referral. The largest group is parents and relatives, who accounted for $42 \%$ ( 223 cases).

Parents were found to notice defects in younger children. Out of the 213 cases first noticed by parents $180(85 \%)$ were by parents of children

Table 5 Source of the referral

\begin{tabular}{lccc}
\hline & \multicolumn{3}{c}{$\begin{array}{l}\text { Contacts in the } \\
\text { chain of referral }\end{array}$} \\
\cline { 2 - 4 } & Immediate & $\begin{array}{l}\text { Percentage of } \\
\text { contacts }(\boldsymbol{n}=691)^{\star}\end{array}$ & $\begin{array}{l}\text { Percentage of } \\
\text { children }(\boldsymbol{n}=525)\end{array}$ \\
\hline Source $(\boldsymbol{n}=525)$ & $38 \%$ & $50 \%$ \\
Heneral practitioner & $47 \%$ & $29 \%$ & $38 \%$ \\
PMT visitor & $24 \%$ & $9 \%$ & $12 \%$ \\
CMO or SMO & $11 \%$ & $7 \%$ & $9 \%$ \\
School nurse & $8 \%$ & $4 \%$ & $5 \%$ \\
Paediatric service & $3 \%$ & $7 \%$ & $9 \%$ \\
Optician & $4 \%$ & $2 \%$ & $3 \%$ \\
Other & $1 \%$ & $100 \%$ & $131 \% \star$ \\
Total & $2 \%$ & & \\
\hline
\end{tabular}

$\star$ In 136 cases more than one contact was made.

Table 6 Hospital diagnosis

\begin{tabular}{llcc}
\hline & $\begin{array}{l}\text { Number of } \\
\text { diagnoses }\end{array}$ & $\begin{array}{l}\text { Percentage of } \\
\text { diagnoses }(\boldsymbol{n}=755)^{\star \star}\end{array}$ & $\begin{array}{l}\text { Percent of } \\
\text { cases }(\boldsymbol{n}=525)\end{array}$ \\
\hline Normal & 109 & $14 \%$ & $21 \%$ \\
Hyperopia & 143 & $19 \%$ & $27 \%$ \\
Strabismus & 118 & $16 \%$ & $22 \%$ \\
Heterophoria & 98 & $13 \%$ & $19 \%$ \\
Astigmatism & 56 & $7 \%$ & $11 \%$ \\
Epicanthus & 53 & $7 \%$ & $10 \%$ \\
Amblyopia & 44 & $6 \%$ & $8 \%$ \\
Myopia & 43 & $6 \%$ & $8 \%$ \\
NLD stenosis & 19 & $3 \%$ & $3 \%$ \\
Chalazion & 14 & $2 \%$ & $2 \%$ \\
Conjunctivitis & 12 & $2 \%$ & $9 \%$ \\
Others & 46 & $100 \%$ & $144 \% \star \star$ \\
Total & $755 \star \star$ & & \\
\hline
\end{tabular}

$\star$ Nasolacrimal duct stenosis. ${ }^{\star}$ In 186 cases more than one diagnosis was given. aged under 5 . When a defect was first noticed by a relative, it was usually by the mother.

The rest of the initiating may be divided into two main groups: the family health care team health visitor and general practitioner - and school health care team - physiological measurement technician (PMT), school nurse, and school medical officer (SMO). Of the 138 patients first detected by family health carers $130(94 \%)$ were aged under 5. In the 5-11 age group, the school health carers found $54 \%$ of cases.

Of the 525 patients referred to the eye department 201 had their first contact with a health visitor. Of these children 54 were aged under 1 year and 69 were aged 3 years, corresponding to the nine months and 3.5 years' screening.

Table 4 lists the reasons for referral. In 31 cases two reasons were given, so that the table shows more reasons than there were children. The reasons for referral were classified by the symptoms, in some cases with anatomical locations. Squint was the most important reason for referral (319 cases, $57 \%$ ) followed by poor vision (106 cases, $19 \%$ ).

On average the children had to wait 63 days (range 0 to 289 days) between referral and the outpatient appointment; 480 cases $(91 \%)$ waited less than three and half months. Only $2 \%$ had to wait more than 6 months. There was no difference between city area and county area in waiting time.

The sources of the referrals are summarised in Table $5,47 \%$ of children were finally referred by their general practitioner. Of the remaining cases $24 \%$ were referred by a health visitor and $11 \%$ by a PMT. $74 \%$ of the children were referred after contact with just one agent, and a further $21 \%$ were referred after contact with two agents. Three contacts were made by $5 \%$ of the children and four contacts by less than $1 \%$. No child had more than four health service contacts prior to referral.

Table 6 shows the diagnoses given at the ophthalmological outpatient consultation. Since 186 cases were given more than one diagnosis, the figures do not correspond to the total number of cases; 109 cases were normal. The most frequent diagnosis was refractive error (hyperopia, myopia, or astigmatism (242, 32\%), followed by strabismus, including heterophoria, $(216,29 \%)$. Amblyopia accounted for $6 \%$ (44 cases). Since the treatment of amblyopia becomes less effective by 5 or 6 years of age and largely ineffective by 9 years of age, ${ }^{7}$ the age of detection of each case of amblyopia was determined. Thirty cases $(67 \%)$ were found before the age of 5 years, 10 cases $(23 \%)$ were found aged between 5 to 8 years, and four cases (9\%) were found aged over 8 years. This indicates that in a number of children the condition had been missed at an earlier screening check. Thirteen $(30 \%)$ of the cases of amblyopia were due to strabismus, 12 (27\%) were due to anisometropia, and $13(30 \%)$ were due to mixed strabismus and anisometropia. In the cases of amblyopia due to strabismus or mixed strabismus and anisometropia $20(77 \%)$ were detected before the age of 5 years, whereas only six $(50 \%)$ of those due solely to anisometropia were detected by that age.

Table 7 shows the accuracy of referral by 
Table 7 Accuracy of referral categorised by the reason for the referral and the immediate source of the referral: percentages with (totals in parentheses)

\begin{tabular}{|c|c|c|c|c|c|c|c|c|}
\hline \multirow[b]{2}{*}{ Reason } & \multicolumn{7}{|c|}{ Source of referral } & \multirow[b]{2}{*}{ Total } \\
\hline & $G P$ & $\begin{array}{l}\text { Health } \\
\text { Visitor }\end{array}$ & $P M T$ & $\begin{array}{l}\text { CMO or } \\
\text { SMO }\end{array}$ & $\begin{array}{l}\text { Paediatric } \\
\text { service }\end{array}$ & $\begin{array}{l}\text { School } \\
\text { nurse }\end{array}$ & Others & \\
\hline $\begin{array}{l}\text { Squint } \\
\text { Poor vision } \\
\text { Runny eye } \\
\text { Lump on lid } \\
\text { Epicanthus } \\
\text { Family history } \\
\text { Other } \\
\text { Total }\end{array}$ & $\begin{array}{rr}64 \% & (137) \\
85 \% & (41) \\
91 \% & (22) \\
94 \% & (18) \\
86 \% & (7) \\
0 \% & (2) \\
71 \% & (38) \\
72 \% & (265)\end{array}$ & $\begin{array}{ll}42 \% & (89) \\
58 \% & (27) \\
- & \\
- & \\
0 \% & (1) \\
40 \% & (5) \\
83 \% & (6) \\
46 \% & (128)\end{array}$ & $\begin{array}{l}63 \%(51) \\
100 \%(10) \\
- \\
- \\
- \\
- \\
- \\
69 \%(61)\end{array}$ & $\begin{array}{l}68 \%(31) \\
80 \%(10) \\
-\quad 100 \%(1) \\
- \\
- \\
-71 \%(42)\end{array}$ & $\begin{array}{r}75 \%(4) \\
0 \% \text { (1) } \\
100 \% \text { (1) } \\
100 \%(1) \\
100 \% \text { (1) } \\
100 \% \text { (1) } \\
56 \% \text { (15) } \\
63 \%(24)\end{array}$ & $\begin{array}{l}100 \%(1) \\
100 \%(13) \\
- \\
- \\
- \\
- \\
0 \%(1) \\
93 \%(15)\end{array}$ & $\begin{array}{l}80 \%(6) \\
100 \%(4) \\
- \\
-\quad 0 \%(1) \\
-\quad \\
60 \%(1) \\
71 \%(21)\end{array}$ & $\begin{array}{l}58 \%(319) \\
80 \%(106) \\
91 \%(23) \\
95 \%(20) \\
70 \%(10) \\
38 \% \quad(8) \\
67 \%(70) \\
66 \%(556)\end{array}$ \\
\hline
\end{tabular}

referring agents and by the reasons for referral. The overall accuracy of referral was $66 \%$ (367 reasons confirmed), for squint it was $58 \%$ (185) and for poor vision it was $80 \%(85)$. As can be seen from Table 7, the general practitioner was the only agent who referred a large range of eye diseases. The accuracy of referral for poor vision by the PMT (10 cases) and school nurse (13 cases) was $100 \%$, while referral by health visitors for poor vision had $58 \%$ accuracy. For squint the accuracy of referral by health visitors was $42 \%$. Only six cases were immediately referred by opticians (Table 5), though 48 contacts were made by opticians in the referral chain. Poor vision and squint were the leading reasons $(80 \%)$ for referral in this group of patients. When health visitors were the sole referring agent, the accuracy was lowest at the nine months screening. There was a tendency for the accuracy to increase with the child's age.

Table 8 shows the accuracy of referral by the person who first noticed the defect and the reason for referral. Parents and relatives first noticed $240(43 \%)$ of the reasons for subsequent referral and had an overall accuracy of $76 \%$. They first picked up $47 \%$ of all suspected squints and $54 \%$ of all confirmed squints. However, parents and relatives first noticed only $15 \%$ of suspected, and $15 \%$ of confirmed, poor vision cases. The largest number of suspected poor vision cases was found by the health visitor.

\section{Discussion}

The type and quality of the information in the referral letters varied with the referring agents. In the referring letters by general practitioners there were descriptions of symptoms, primary diagnoses, and in some cases, such as those with conjunctivitis, the treatment and efficiency of the treatment. These cases were referred for advice on treatment including some for surgery. Most of the other referring agents tended to refer cases primarily on their account of symptoms. Opticians were more likely than general practitioners to provide details of an ophthalmic examination and indicate the anatomical location of a problem.

Among the reasons for referral patients with red eyes, lump on lid, and runny eyes were the most likely to be referred correctly. The most important reasons for false positive referral in this study were squint and poor vision. This may be because in such cases the examination requires the co-operation of the children, and that is especially difficult to obtain in the very young. Usually the false diagnosis of strabismus was due to epicanthus and facial asymmetry.

Harrison' et al in a study of adult referral found similar types of information in the referral letters from general practitioners and opticians, and, as here, found that general practitioners referred nearly half the cases. The referral systems for children in this survey tended to depend more on the family health carers (HV and GP) and school health carers. The reasons for referral of children were quite different from those for adults. In Harrison and colleagues' survey the most important reasons for referral were visual loss and suspected glaucoma.' The visual loss proved to be due mainly to organic lesions such as cataract and retinal diseases. In our survey the most important reasons for referral were squint and poor vision, the latter mainly due to refractive error or strabismus. In our survey the accuracy of general practitioners' referral for squint (64\% of total 137 reasons) and poor vision $(85 \%$ of 41$)$ were higher than in Harrison and colleagues' study, where they found $52 \%(77)$ and $80 \%(74)$ respectively.'

Shaw $e t a l^{B}$ studied a sample of 1531 cases of amblyopia referred to the Leicester Royal Infirmary and its peripheral clinics. As in this survey, they found that amblyopia due to anisometropia alone was detected at a later age than amblyopia due to strabismus or mixed strabismus and

Table 8 Accuracy of referral categorised by the reason for the referral and the persons who first noticed the defect: percentages with (totals in parentheses)

\begin{tabular}{|c|c|c|c|c|c|c|c|c|c|c|}
\hline \multirow[b]{2}{*}{ Reason } & \multicolumn{7}{|c|}{ Persons who first noticed the defect } & & \multirow[b]{2}{*}{ Total } \\
\hline & $\begin{array}{l}\text { Parents, } \\
\text { Relatives }\end{array}$ & $H V$ & $P M T$ & Patient & $\begin{array}{l}\text { School } \\
\text { nurse }\end{array}$ & $\begin{array}{l}\text { CMO or } \\
S M O\end{array}$ & $\begin{array}{l}\text { Paediatric } \\
\text { service }\end{array}$ & $G P$ & Others & \\
\hline $\begin{array}{l}\text { Squint } \\
\text { Poor vision } \\
\text { Runny eye } \\
\text { Lump on lid } \\
\text { Epicanthus } \\
\text { Family history } \\
\text { Others } \\
\text { Total }\end{array}$ & $\begin{array}{rr}66 \% & (150) \\
81 \% & (16) \\
94 \% & (18) \\
100 \% & (17) \\
100 \% & (7) \\
40 \% & (5) \\
81 \% & (27) \\
76 \%(240)\end{array}$ & $\begin{array}{rr}36 \% & (80) \\
71 \% & (41) \\
100 \% & (1) \\
-\quad & \\
0 \% & (1) \\
33 \% & (3) \\
71 \% & (7) \\
49 \%(133)\end{array}$ & $\begin{array}{l}62 \%(47) \\
100 \%(12) \\
- \\
- \\
- \\
- \\
- \\
69 \%(59)\end{array}$ & $\begin{array}{r}100 \%(5) \\
80 \%(5) \\
-\quad 50 \%(2) \\
50 \%(1) \\
-\quad 5 \%(11) \\
55 \%(24)\end{array}$ & $\begin{array}{l}50 \%(4) \\
94 \%(17) \\
- \\
- \\
- \\
- \\
100 \%(1) \\
86 \%(22)\end{array}$ & $\begin{array}{l}64 \%(14) \\
60 \%(5) \\
-\quad 100 \%(1) \\
- \\
\overline{1} 100 \%(1) \\
67 \%(21)\end{array}$ & $\begin{array}{r}75 \%(4) \\
50 \%(2) \\
100 \%(2) \\
-\quad 0 \%(1) \\
-\quad 50 \%(12) \\
57 \%(21)\end{array}$ & $\begin{array}{l}50 \%(10) \\
100 \%(1) \\
100 \%(1) \\
- \\
- \\
50 \%(4) \\
56 \%(16)\end{array}$ & $\begin{aligned} & 100 \%(5) \\
& 86 \%(7) \\
& 0 \%(1) \\
&- \\
&- \\
&- \\
& 43 \%(7) \\
& 70 \%(20)\end{aligned}$ & $\begin{array}{l}58 \%(319) \\
80 \%(106) \\
91 \%(23) \\
95 \%(20) \\
70 \%(10) \\
38 \%(8) \\
67 \%(70) \\
66 \%(556)\end{array}$ \\
\hline
\end{tabular}


anisometropia. They considered a number of reasons why this may be so, one of which was the lack of any accompanying sign in the anisometropic cases, so that the parents had difficulty in detecting it. That suggestion is supported by this survey. Although parents first noticed $62 \%$ of the amblyopia due to strabismus or mixed strabismus and anisometropia, they first noticed only $17 \%$ of the cases due to anisometropia alone.

Although general practitioners finally referred almost half of all children, not many of the conditions were first found by them. Screening and home visits undertaken by health visitors and eye checks at school performed by the PMT and the school nurse were more important in detecting eye defects. The health visitors played a large part with children aged under 5; the PMT and school nurse were more important for children of school age. When parents first noticed a defect, they sometimes did not take any action for several months, and it was not until the health visitor went to their homes that the referral was actually made.

The higher accuracy of referral first noticed by parents and relatives may be due to a number of factors. Firstly, the parents first noticed the more obvious cases, leaving the health workers to detect the rest. Secondly, the parents have much more contact with their children and therefore have the opportunity to observe the abnormality even when it appeared only inter- mittently, as with intermittent strabismus. Finally, in some families there were other members suffering from similar eye diseases, making the parents more aware of possible eye disease in their children.

Parents and relatives proved to be good at detecting conditions with obvious outward signs, such as squint, running eyes, and lump on the lid. However, they were not so good at noticing poor vision, and it is in this area that the work of the health professionals is especially important.

We thank the consultants of the Leicester Royal Infirmary for their co-operation with this survey. The work was in part supported by the Anne Allerton Fund

1 Harrison RJ, Wild JM, Hobley AJ. Referral patterns to an ophthalmic outpatient clinic by general practitioners and ophthalmic opticians and the role of these professionals in screening for ocular disease. Br Med f 1988; 297: 1162-7.

2 McDonnell J. How do general practitioners manage eye disease in the community? Brf Ophthalmol 1988; 72: 733-6.

3 Brittain GPH, Austin DJ, Kelly SP, A prospective survey to determine sources and diagnosis accuracy of glaucoma referrals. Health Trends 1988; 20: 43-4.

4 Royal College of General Practitioners. Office of Populations Censuses and Surveys and Department of Health and Social Security. Morbidity Statistics From General Practice 1981-82. London: HMSO, 1986: series MB5 no 1.

5 Dart JKG. Eye disease at a community health centre. $\mathrm{Br} \mathrm{Med} \mathcal{F}$ $1986 ; 293 ; 1477-80$.

6 Working Group for the Survey of Leicester. Survey of Leicester 1983: initial report of the survey. Leicester City Council and Leicestershire County Council, 1985.

7 Harley RD. Pediatric ophthalmology. 2nd ed. Philadelphia: Saunders, 1983.

8 Shaw DE, Fielder AR, Minshull C, Rosenthal AR. Amblyopia -factors influencing age of presentation. Lancet 1988; ii: 207- 